\title{
S5ynthesis
}

International Scientific Conference of IT and Business-Related Research

\section{CONTEMPORARY ELECTRONICS WITH LTSPICE AND MATHEMATICA}

\section{SAVREMENA ELEKTRONIKA SA PROGRAMSKIM PAKETIMA LTSPICE I MATHEMATICA}

\author{
Miroslav Lutovac ${ }^{1}$, Vladimir Mladenović ${ }^{2}$ \\ ${ }^{1}$ Singidunum University, Danijelova 32, Belgrade, Serbia \\ ${ }^{2}$ Faculty of Technical Sciences, Čačak, University of Kragujevac, Serbia
}

\begin{abstract}
:
This paper presents a new concept of teaching analog and digital electronics courses to electrical engineering students, which uses a computer algebra systems and numeric solvers. The fundamentals of analog measurements, analog data collection, and digital data collection are included in this one-semester course. Computer algebra system (CAS) is used to formulate circuit equations and prepare for symbolic solving and thus completely specify an electrical circuit using Mathematica as CAS. Exercises introduce diodes, transistors, operational amplifiers, and their use in simple real-world circuits. Using the symbolic expressions, it is possible to design and optimize specific circuits. LTSpice is used for simulating final solutions based on large collection of existing circuit models. In such a way, the students are exempt from manual solving of large systems of equations and are focused on understanding the functional models and simulation of complex electrical systems with complex devices. Finally, LABVIEW programming allows each student to create a virtual instrument for data collection and analysis.
\end{abstract}

\section{Key words:}

electrical engineering, computer algebra system, analog and digital electronics, education.

\section{Apstrakt:}

Ovaj rad predstavlja novi koncept u nastavi analogne i digitalne elektronike namenjen studentima elektrotehnike, koji se oslanja na upotrebu sistema računarske algebre i solvera. Osnove analognih merenja, analognog prikupljanja podataka i digitalnog prikupljanja podataka obuhvaćene su ovim jednosemestralnim kursom. Sistemi računarske algebre (CAS) pružaju mogućnost za analitičku obradu geometrije, simboličko rešavanje algebarskih sistema korišćenjem programskog paketa Mathematica. Na vežbama se uvode diode, tranzistori, operativna pojačala, i njihova primena u elektronskim kolima za rad u realnom vremenu. Na osnovu simboličkih izraza moguće je kreirati i optimizovati određena elektronska kola. Programski paket LTSpice koristi se za simulaciju elektronskih kola i za predviđanje ponašanja na osnovu velikog broja postojećih modela. $\mathrm{Na}$ taj način su studenti oslobođeni od ručnog rešavanja velikih sistema jednačina i više pažnje se posvećuje razumevanju funcionalnih modela i simulaciji složenih električnih sistema. Konačno, programiranje u LABVIEW-u omogućava studentima da kreiraju virtuelne intstrumente za prikupljanje i analizu podataka.

\section{Key words:}

elektrotehnika, sistemi računarske algebre, analogna i digitalna elektronika, obrazovanje.

\section{Acknowledgements.}

This work was supported by the Ministry of Education, Science and Technological Development of the Republic of Serbia under Grant TR 32023.

\section{INTRODUCTION}

In electrical engineering education, it is important to understand electronics, control theory, telecommunications, signal and systems, power electric systems, and many other topics related to electrical engineering. Educators are focused on helping the students to gain understanding of the subject (Tosic, 2010). Usually, the settings of equations that describe systems are done manually, and lots of time is spent on solving system of equations. In some cases, an expert knowledge is required for finding some functions such as the negative feedback loops of the existing network, such as open-loop gain and the feedback factor $\beta$. On the other hand, many students are lacking mathematical knowledge and are expecting to understand without too much effort for solving homework, following only simple procedures.

Training new electronics engineers presents many challenges for practical lessons in analog electronics, where students get a thorough understanding of real-world practices in electronic engineering. This approach consists of creating a virtual environment so that the design process involves theoretical concepts from the students' lessons and appoints challenges with respect to efficient low-cost design. This method brings student interest in practical matters in electronics, mathematics, and software engineering that can respond to the key global technical challenges, such as energy efficient electrical devices.

The main aim of this paper is to show that complex mathematical examples can be introduced in such courses by drawing the attention of students only to basic theory and basic theorems while all complex mathematical simplifications can be performed using the computer algebra systems and numeric simulators can be used for verifying the obtained solutions.

\section{LTSPICE}

New electronic device can be tested without a real printed circuit board or a soldering iron. Circuit simulation can save money, time, and efforts when analyzing the existing circuit, designing a new device, or modifying the existing electronic solutions (Kraus, 2015). The SPICE program was developed before 1980 at the Berkeley University using FORTRAN programing language. The version for PC computers was called PSPICE. 
Linear Technologies, one of the leading manufacturers of electronic components, which offers a free full SPICE-program named LTspice without any restrictions. It can be downloaded from the web without any problems or fees, but its usage is a little tricky - a mixture of command lines, GUI (graphics user interface), and mouse clicks. There are many tutorials available for students and engineers.

In the transient and steady-state analysis, we usually start by writing circuit equations using the Ohm's law, the Kirchhoff's current law (the net current entering a node is zero), and the Kirchhoff's voltage law (the algebraic sum of the voltages for any closed path in an electrical circuit is equal to zero). Because the current voltage relationships for inductances and capacitances involve integrals and derivatives, the equations can be converted to pure differential equations by differentiating with respect to time. The study of transients and steady- state requires solving differential equations, which can be unpleasant for young students of electrical engineering and electronics. The main feature of circuits can be described using the existing circuits from text-books (Hambley, 2011; Agarwal, 2005), such as an amplifier with a single transistor, presented in Fig. 1.

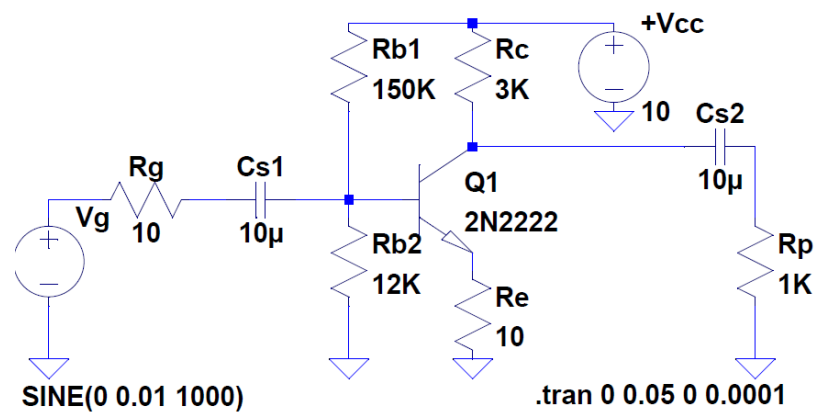

Fig. 1 Common emitter amplifier
The analysis can start using one of the 100s of demo circuits available on the site of Linear Technology or by using the schematic editor to create your design redrawing schematic from the book. LTspice contains macromodels for most LTC power devices, and almost all manufacturers' have prepared Datasheetas with device models for instant use in the SPICE analysis. Some components have an available database of manufacturers' attributes (resistors, capacitors, inductors, diodes, bipolar transistors, MOSFET transistors, JFET transistors). Before running a simulation, the type of analysis should be defined (small signal AC, DC sweep, noise, DC transfer function, DC operating point). The analysis of an electrical circuit includes the determination of voltages and currents given the element numeric values.

Transient simulation of common emitter amplifier from Fig. 1 is presented in Fig. 2. Fig. 3 and it illustrates frequency domain simulation of common emitter amplifier.

The Fig. 3 shows that the circuit presented in Fig. 1 has transfer function poles at very high frequencies although we cannot see capacitance that are reasons for the high frequency poles. Parasitic capacitance between base and emitter and base and collector exit in transistor model Q1 2N2222, and thus the simulation is very close to the real measured characteristic of the circuit from Fig. 1.

\section{DESIGN BY ANALYSIS}

Design of a specific device starts using the circuit configuration given in some books and journals. The concept of abstraction is useful to unify the set of engineering simplifications made in the design. Usually, the problem is under-constrained, and thus, it has many answers.

An interactive design and numeric only analysis allows designers to quickly iterate the proposed design solution and evaluate the merits of different ideas, compare alternatives, and identify design weaknesses before a costly production has been

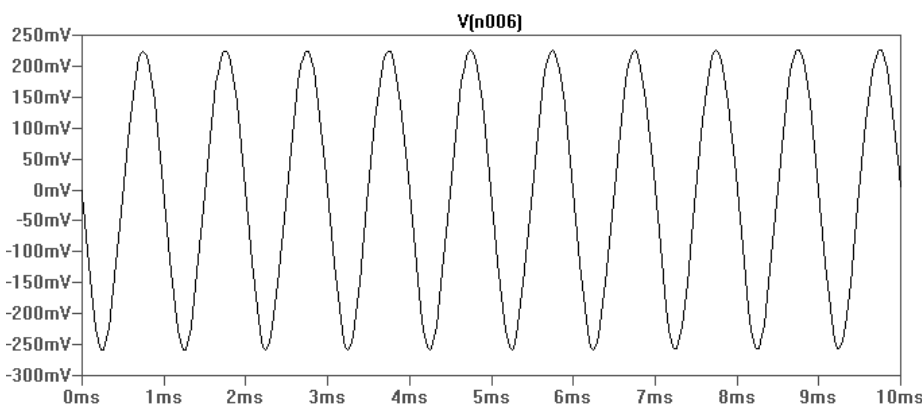

Fig. 2 Transient simulation of the common emitter amplifier

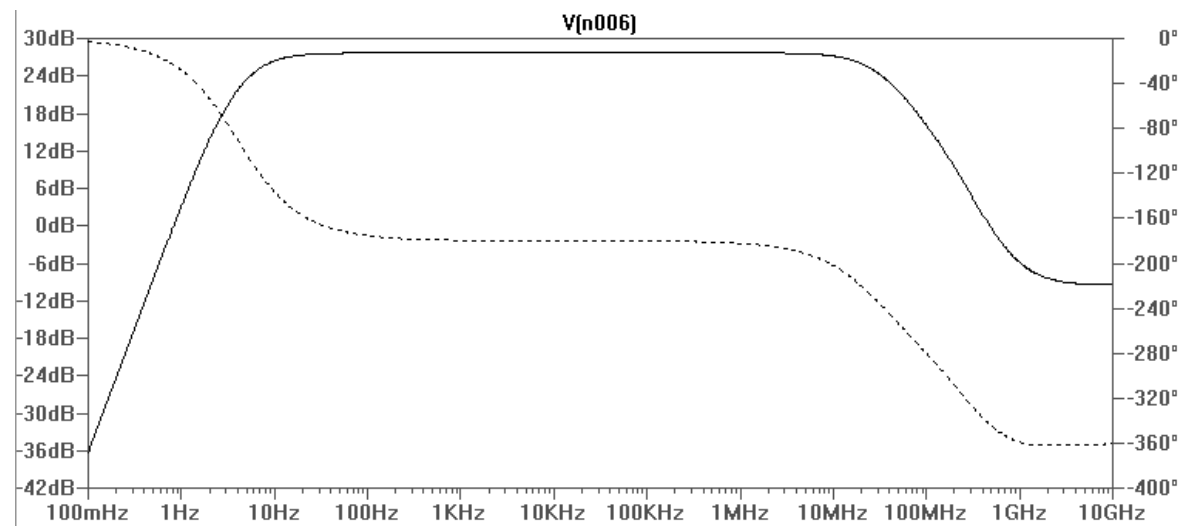

Fig. 3 Frequency domain simulation of the common emitter amplifier 
done. A unique approach called design space is introduced in (Lutovac, 2001). This approach enables to study the performance of structures by varying design parameters in a cost effective way. This signifies the transition from the traditional design by formula to design by analysis approach. However, there are still many practical issues that have to be addressed in order to get the real implementation.

The following example proposes the symbolic design that provides the collector voltage at half the available supply voltage. The design assumes to find a resistor value from theavailable set of values. After drawing the scheme of the circuit, a set of equations can be derived using the Ohm's law, the Kirchhoff's current law, and the Kirchhoff's voltage law, as shown in Fig. 4, which is programmed in Mathematica (Wolfram, 2003). Two unknown variables are the base current Ib and the voltage between collector and emitter nodes Vce, and thus a set of two equations is required (set of equations is denoted by equDC):

$$
\begin{gathered}
\text { equDC }=\left\{\frac{\mathrm{Vcc}}{\mathrm{Rb} 1}-\mathrm{Ib}-\frac{(\mathrm{Vbe}+\mathrm{Ib}(1+\mathrm{b}) \mathrm{Re})}{\mathrm{Rb} 2}==0,\right. \\
\mathrm{Vcc}-\mathrm{b} \mathrm{RCIb}-\mathrm{Vce}-\mathrm{Ib}(1+\mathrm{b}) \mathrm{Re}=0\}
\end{gathered}
$$

Fig. 4 Set of the circuit equations of the common emitter amplifier

The general solution with all parameters specified as symbols can be derived using Solve built-in Mathematica command

$s 1=$ Solve $[$ equdC, $\{\mathrm{Ib}, \mathrm{Vce}\}]$.

Solutions are illustrated in Fig. 5.

$$
\begin{gathered}
\left\{\left\{\mathrm{Ib} \rightarrow-\frac{\mathrm{Rb} 1 \mathrm{Vbe}-\mathrm{Rb} 2 \mathrm{VCC}}{\mathrm{Rb} 1(\mathrm{Rb} 2+\mathrm{Re}+\mathrm{b} \mathrm{Re})},\right.\right. \\
\left.\left.\mathrm{Vce} \rightarrow \mathrm{VCC}+\frac{(\mathrm{b} \mathrm{RC}+\mathrm{Re}+\mathrm{b} \mathrm{Re})(\mathrm{Rb} 1 \mathrm{Vbe}-\mathrm{Rb} 2 \mathrm{VCC})}{\mathrm{Rb} 1(\mathrm{Rb} 2+\mathrm{Re}+\mathrm{b} \mathrm{Re})}\right\}\right\}
\end{gathered}
$$

Fig. 5 Set of the circuit equations of the common emitter amplifier

Some parameters can be arbitrary chosen, while others can be retained in a symbolic form, $\mathbf{R b} 2$, and used for the design or optimization. Suppose that the constrain is to have the collector of half of the supply voltage, which can be specified as unknown voltage $\mathbf{V p}$, equal to the voltage between collector and emitter for the solution $\mathbf{s} 1$

$$
\mathrm{Vp}=\mathrm{Vce} / . \mathrm{s} 1[[1]]
$$

The new solution of this constrain is in terms of $\mathrm{Rb} 2$

$$
\mathrm{s} 2 \text { = Solve }[\mathrm{Vp}==\mathrm{Vcc} / 5, \mathrm{Rb} 2] / / \mathrm{Simplify}
$$

By using the chosen values of all parameters, the voltage at the collector node can be presented as a function of $\mathbf{R b} 2$, as illustrated at Fig. 6.

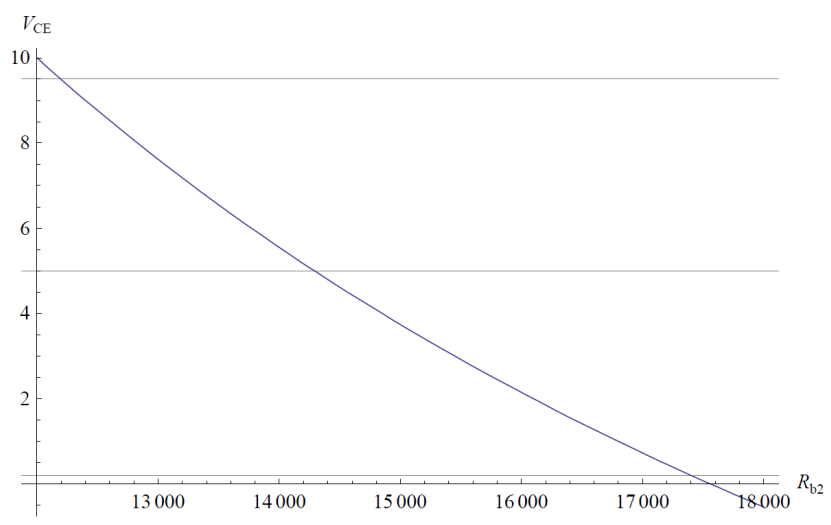

Fig. 6 The collector voltage $\mathbf{V} \mathbf{C E}$ as a function of $\mathbf{R b} 2$

As can be seen in Fig. 6, the transistor is in active region for resistor values between $13 \mathrm{k} \Omega$ and $17 \mathrm{k} \Omega$. It is worth noting that the classic design starts with the assumption that transistor is in active region and the assumption is tested at the end of the analysis.

\section{SYMBOLIC ANALYSIS}

Similar approach is possible for transient simulation of common emitter amplifier from Fig. 1 and the frequency domain simulation of the circuit. However, from the educational viewpoint, a pictorial representation of the circuit is required. This can be done by entering the knowledge for drawing discrete electronic elements (Fig. 7)

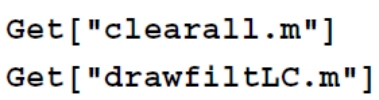

Fig. 7 Entering the knowledge for drawing components

In order to add or remove the element, drawing grid is defined as in Fig. 8.

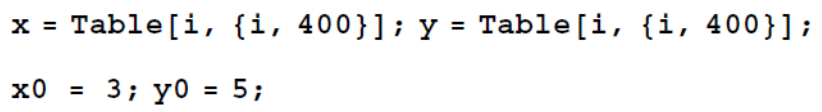

Fig. 8 Setting the drawing grid

An example of the schematic description is illustrated in Fig. 9.

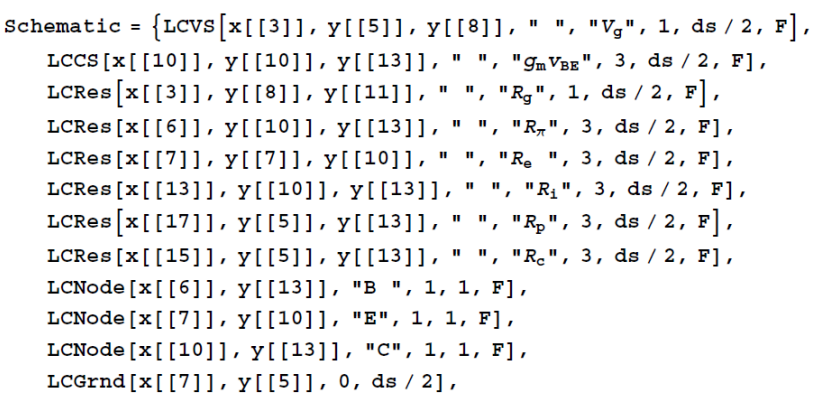

Fig. 9 Part of schematic description 
The command

Show [Schematic /. smenadrawLC /. $\{d s \rightarrow 5, F \rightarrow 10\}$ ]

can be used for the schematic drawing, and Fig. 10 illustrates the equivalent small-signal model of the amplifier with common emitter and the negative feedback Re. Latter, parasitic capacitance can be added as well as the capacitors for separating DC (direct current) and AC (alternating current) circuitry.

The modified nodal analysis is used for setting circuit equation, and it is very similar to the Kirchhoff's current law (identify all nodes; describe all currents entering nodes - algebraic sum of the currents entering a node in a circuit is equal to zero). This way, by adding parasitic capacitances, we will not increase the number of equations. It is possible to identify only three nodes that are transistor ports (base, emitter, and collector) in the given paper.

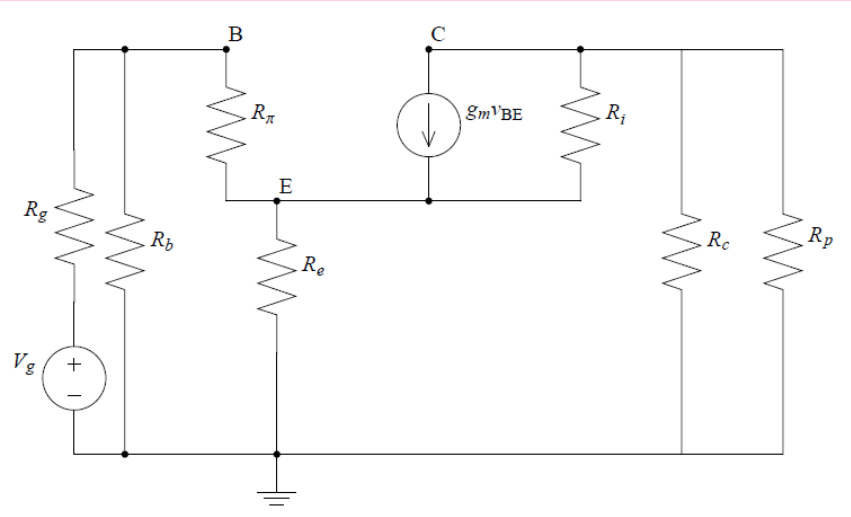

Fig. 10 Equivalent small-signal model of the amplifier with common emitter

Fig. 11 illustrates the simplified set of equations assuming that influence of the capacitors can be neglected.

$$
\begin{aligned}
& \text { equ }=\left\{\frac{V B-V g}{R g}+\frac{V B}{R b 12}+\frac{V B-V E}{R p i}=0,\right. \\
& \frac{V E-V B}{R p i}+\frac{V E}{R e}-g m(V B-V E)+\frac{V E-V C}{R i}==0 \\
& \left.g m(V B-V E)+\frac{V C}{R p}+\frac{V C}{R C}+\frac{V C-V E}{R i}=0\right\}
\end{aligned}
$$

Fig. 11 Set of the circuit equations of small-signal model of the common emitter amplifier
Transfer function can be derived after using the command for solving system of equations:

$$
\text { s1 = Solve [equ, }\{\mathrm{VE}, \mathrm{VB}, \mathrm{VC}\}]
$$

Fig. 12 presets simplified transfer function.

Assuming that some resistances can be neglected assuming that they have infinite values, a more simplified transfer function can be derived, as presented in Fig. 13.

$$
-\frac{\beta R_{p}}{r_{\pi}+R_{e}+\beta R_{e}+R_{g}}
$$

Fig. 13 Transfer function for $\mathrm{Ri} \rightarrow \infty, \mathrm{Rb} 12 \rightarrow \infty, \mathrm{Rc} \rightarrow \infty$

The result presented in Fig. 13 is more complicated when all capacitors are used, see Fig. 14.

The transfer function derived for $\mathrm{Ri} \rightarrow \infty, \mathrm{Rb} 12 \rightarrow \infty, \mathrm{Rc} \rightarrow \infty$ can be plotted in terms of the frequency as illustrated in Fig. 15. It can be observed in the figure that the transfer function has a transfer function zero at the origin, and two zeros and very high frequencies. Also, it can be concluded that the transfer function has a pole near $8 \mathrm{~Hz}$, and two poles at higher frequencies.

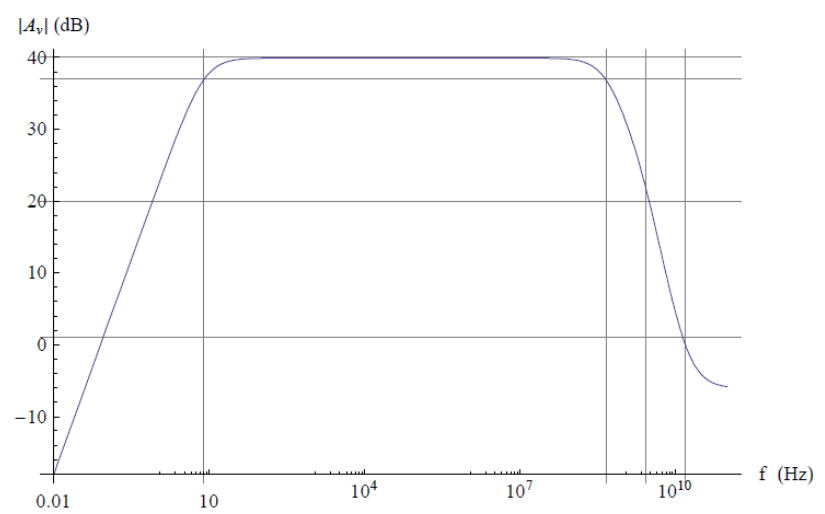

Fig. 15 Attenuation of the common emitter amplifier

Same conclusions can be drawn considering the phase response of the transfer function, as shown in Fig. 16.

$\{(\operatorname{Rb} 12 \operatorname{RC} \operatorname{Rp}(\operatorname{Re}-\operatorname{Ri} \beta)) /$

$(\operatorname{Rg}(\operatorname{Rp}(\operatorname{Ri} \mathrm{Rp} i+\operatorname{Re}(\operatorname{Ri}+\operatorname{Rp} i+R i \beta))+\operatorname{RC}((\operatorname{Ri}+\operatorname{Rp}) \operatorname{Rp} i+\operatorname{Re}(\operatorname{Ri}+\operatorname{Rp}+\operatorname{Rp} i+\operatorname{Ri} \beta)))+$ $\mathrm{Rb} 12(\mathrm{Rp}(\mathrm{Ri}(\mathrm{Rg}+\mathrm{Rp} i)+\mathrm{Re}(\mathrm{Rg}+\mathrm{Ri}+\mathrm{Rp} i+\mathrm{Ri} \beta))+$

$R C((R i+R p)(R g+R p i)+R e(R g+R i+R p+R p i+R i \beta))))\}$

Fig. 12 Transfer function of small-signal model of the common emitter amplifier

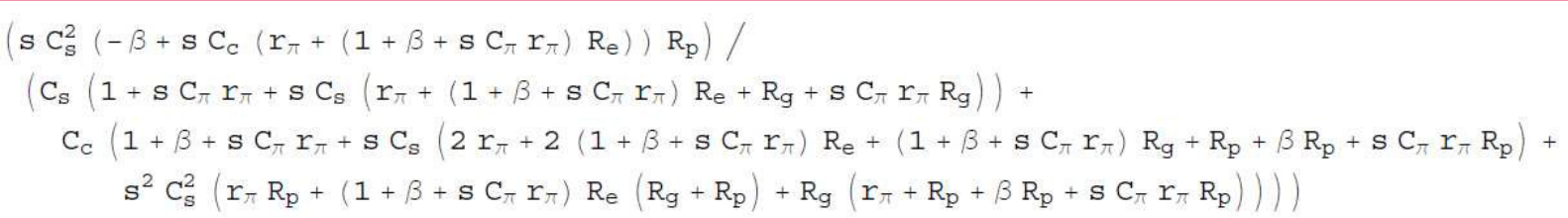

Fig. 14 Set of the circuit equations of the common emitter amplifier 


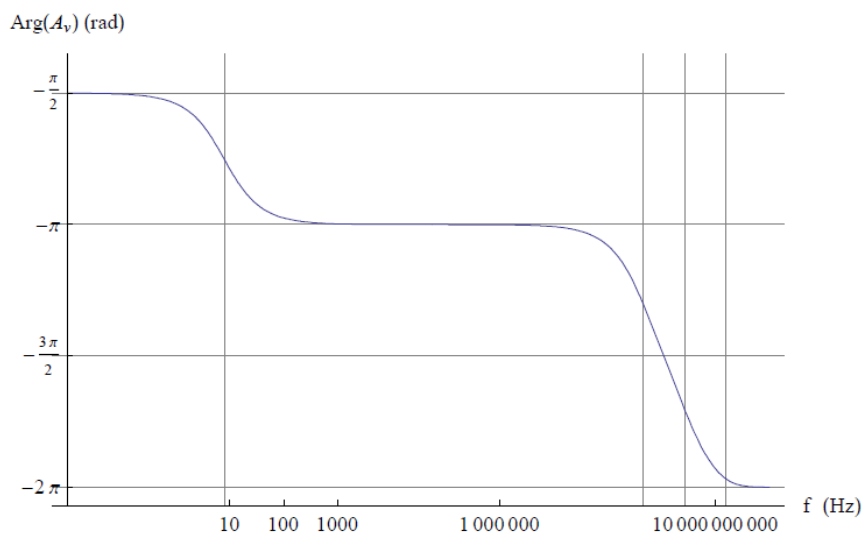

Fig. 16 Phase response of the transfer function of the common emitter amplifier

The exact values of transfer function zeros and poles can be derived from roots of polynomials in the numerator and denominator. Numeric values are presented in Figs. 17 and 18.

$\left\{\{s \rightarrow 0\},.\left\{s \rightarrow-1.10554 \times 10^{11}\right\},\left\{s \rightarrow 9.04537 \times 10^{10}\right\}\right\}$

Fig. 17 Zeros of the transfer function of the common emitter amplifier

$\left\{\left\{\mathrm{s} \rightarrow-1.71654 \times 10^{10}\right\},\left\{\mathrm{s} \rightarrow-2.93464 \times 10^{9}\right\},\{\mathrm{s} \rightarrow-49.5049\}\right\}$

Fig. 18 Poles of the transfer function of the common emitter amplifier

This new approach demonstrates that it is possible to calculate in minutes or seconds the results that would be almost impossible by paper and pencil using computer algebra systems, such as Mathematica. Closed form expressions derived using this methodology can be used for optimization or energy efficient design. In order to reduce the size of chips without needing significant design changes, the same methodology can be used for the design with programmable analog devices (Lutovac, 2013).

\section{ELECTRONIC DEVELOPMENT PLATFORMS AND VIRTUAL INSTRUMENTATION}

Several development platforms can be used in teaching electronics. The Analog System Lab Kit PRO (ASLK PRO) exposes students to the analog electronics and mixed-signal processing (communications). The kit comes with 14 step-by-step experiments and the course can be adapted for an undergraduate or postgraduate curriculum (Negative feedback in amplifiers, Building instrumentation amplifier, Understanding transient response, frequency response, DC transfer characteristics, Hysteresis in switching circuits, Integrators and differentiators, Filters and frequency response, tuning filters, Function generator design, voltage controlled oscillator, Phase lock loop functionality, Automatic gain / volume control, Characteristics of DCDC converter, Design and study low dropout regulator, Digitally controlled gain stage amplifier, and Digitally programmable square and triangular wave generator/oscillator). As part of the lab course, students will build analog systems using analog integrated circuits and study their macro models, characteristics and limitations.

A valuable platform for developing complex electronic devices is the Raspberry Pi (McManus, 2013). It can be used like any computer for music, games, photo-editing, and word processing, but also as a gateway into programming and electronics. Even more, all notebooks presented $\mathrm{n}$ this paper can be evaluated at Raspberry Pi. The development platform can be used by adding SD card, screen, mouse, and keyboard, and cable for connecting to the Internet. Any PC computer can also be used as an instrument.

In addition, LABVIEW environment allows each student to create a virtual instrument for data collection and analysis.

\section{SUMMARY}

In recent years, classical electrical engineering education has focused largely on mathematics, manual derivations, and experiments, but not on understanding how electronic devices work, or how one can use them to create new complex devices and inventions based on mathematical models. The new approach is mainly targeted to combine understandings of simple devices, integrate models into large systems, and use computer algebra systems instead of manual derivation of responses. By combining visual interpretation from mathematical models with simulating numeric tools, electronic kits, and virtual instrumentation, the processes of analysis and design are integrated into a unique development environment that can be used by the students of the first and second year of electrical engineering.

\section{REFERENCES}

Agarwal, A., \& Lang, J.H. (2005). Foundations of Analog and Digital Electronic Circuits. Amsterdam: Elsevier.

Gunthard Kraus. (2010). SPICE-Simulation using LTspice IV. Retrieved March 29, 2015, from http://www.ieca- inc.com/ images/Spice-Simulation_Using_LTspice_Part_1.pdf

Hambley, A.R. (2011). Electrical Engineering, Principles and Applications. Upper Saddle River: Prentice Hall.

Lutovac, M.D., Tošić, D.V., \& Evans. B.L. (2001). Filter Design for Signal Processing Using MATLAB and Mathematica. Upper Saddle River: Prentice Hall.

Lutovac, M., Pavlovic, V., \& Lutovac. M. (2013). Automated Knowledge Based Filter Synthesis Using Gegenbauer Approximation and Optimization of Pole-Q Factors. Electronics \& Electrical Engineering, 19 (9). DOI: http://dx.doi. org/10.5755/j01.eee.19.9.2516

McManus, S., \& Cook, M. (2013). Raspberry Pi for dummies. Hoboken, NJ: John Wiley \& Sons.

Rao, K.R.K., \& Ravikumar, C.P. (2012). Analog System Lab Kit PRO MANUAL. Retrieved March 29, 2015, from http:// www.farnell.com/datasheets/1681419.pdf.

Tosic, D. V. (2010). Graph-theoretic formulation of equations for electrical circuits with Mathematica. The IPSI BgD Transactions on Internet Research, 6(1), 10-17.

Wolfram, S. (2003). The Mathematica book. Champaign, IL: Wolfram Media. 